ÁREA ABIERTA. Vol. 14, n 3 . Numero monográfico "Feminismo, estudios sobre mujeres y cultura audiovisual". Noviembre 2014

http://dx.doi.org/10.5209/rev_ARAB.2014.v14.n3.45851

"MUJERES, VIOLENCIA Y POSFEMINISMO EN LOS VÍDEOS DE MADONNA"

AUTORAS: Iolanda TORTAJADA GIMÉNEZ y Nuria ARAÜNA I BARÓ, Universitat Rovira i Virgili, Tarragona

\title{
Mujeres, violencia y posfeminismo en los vídeos de Madonna
}

\author{
Women, violence and postfeminism \\ in Madonna's music videos
}




\section{RESUMEN:}

Varios autores y autoras identifican la década de los noventa como un punto de inflexión en la representación del género en los medios de comunicación. Desde entonces, por lo que a las mujeres respecta, se detecta un mayor repertorio de representaciones $y$, especialmente, en estos últimos años, una redefinición del concepto de empoderamiento. La capacidad que hoy se atribuye a las mujeres aparece vinculada a su agencia sexual, pero también a la incorporación de comportamientos agresivos y del ejercicio de la violencia, todo ello dentro de un paradigma marcadamente individualista. Para ilustrar cómo se manifiestan estas transformaciones y poner en evidencia hasta qué punto éstos son los rasgos más destacables en la configuración de las nuevas feminidades, hemos creído oportuno analizar algunos vídeos musicales de Madonna centrándonos especialmente en los aspectos del empoderamiento ligados a actitudes violentas. Hemos escogido a Madonna por su estatus de icono de la cultura popular, por su larga trayectoria musical y por el interés que ha despertado entre los académicos y las académicas para el estudio de cuestiones de género. A partir del análisis de cuatro de sus vídeos musicales —dos anteriores a la primera mitad de la década de los '90 y dos posteriores al año 2000-, hemos constatado como Madonna, dentro de los códigos de representación que se agrupan bajo la etiqueta del posfeminismo, ha modificado su caracterización con relación a la violencia, pasando de ocupar una posición de víctima a un papel de verdugo y vengadora. Como víctima, y a pesar de su poder de seducción, no puede escapar de su condición de subordinación. Sin embargo, reivindicarse como mujer dura le va a permitir tanto una venganza individual (y suicida) como, echando mano de la seducción, revalidarse en el ideal de mujer triunfadora posfeminista.

\section{Palabras clave:}

Nuevas feminidades, posfeminismo, vídeos musicales, Madonna, violencia.

\section{ABSTRACT:}

Several authors identify the 1990s as a turning point in gender representation in the media. Women have been depicted more diversely since then. In recent years, this has had a bearing on the idea of empowerment, which has been redefined as far as women's representations are concerned. This renewed capability women are currently ascribed appears to be linked to their equally revived sexual agency -but also to an aggressive kind of behavior and to violence- within an overall individualistic framework. By way of illustration of how this transformation has manifested itself, we think Madonna's music videos to be much to the point as to how significant these traits have become in shaping today's new femininities and, more specifically, as to how empowerment is being increasingly linked to violent attitudes and demeanors. We have chosen Madonna in view of her being a truly global popular culture icon, but also because of her long career in pop music and how much interest she has drawn from scholars in gender studies. In an analysis of four of her music videos -two from the early 1990s and two from the 2000s- we have found how, over the years, Madonna has changed the way she characterizes herself vis-à-vis violence, 
from a position of violence's victim to one of executioner/avenger. As a victim, in spite of the power of her seductiveness, she could not escape her subordinated condition. However, in her later vindication as a tough woman, she (her on-screen persona, that is) overindulges in a personal, individual (and suicidal) revenge on men, while (resorting to seduction) reaffirming herself in her (quintessentially post-feministic) role as a triumphant female.

\section{Keywords:}

New Femininities, Postfeminism, Music Videos, Madonna, Violence. 


\section{Posfeminismo y feminidades agresivas}

En la actualidad, los medios de comunicación nos ofrecen un abanico de representaciones de género contradictorias, mostrándonos discursos sobre el poder de las chicas que esos mismos medios yuxtaponen a otros relatos e imágenes que dan un nuevo ímpetu a las desigualdades (Gill y Scharff, 2011). Esta ambivalencia de las representaciones mediáticas (Kellner, 2003) se produce en un contexto posfeminista, es decir, en un entorno que se caracteriza por una incorporación engañosa de algunos rasgos del feminismo que consiste en presentarlo como un movimiento que ha visto cumplidos sus objetivos y reivindicaciones para, así, relegarlo al pasado (McRobbie, 2004). El posfeminismo es también un potencial objeto de un análisis crítico (Gill y Scharff, 2011) que ayudaría a reconocer y estudiar los cambios acaecidos en las representaciones de las mujeres en las décadas recientes (Lotz, 2001).

Entre otros rasgos novedosos y estables, el posfeminismo se caracteriza por la representación de las mujeres como sujetos sexuales (que desean y que, sobretodo, quieren ser deseadas), por la sexualización de la cultura y por un énfasis en la diferencia natural entre sexos, en el individualismo y en el consumismo (Gill, 2007). Incorpora parcialmente las reivindicaciones feministas, pero lo hace redefiniendo el concepto de empoderamiento y la conexión entre consumismo y feminismo de tal modo que política y activismo quedan desplazados por conceptos menos combativos como el "estilo de vida" o la "actitud" (Lotz, 2001). El empoderamiento se entiende así como un resultado vinculado a la agencia sexual de las mujeres en un paradigma individualista, lo que lo vacía de contenido político (Gill, 2008). Bien podríamos decir con Radner (2011) que, precisamente por su inclusión de motivos individualistas y pragmáticos y del autoconvencimiento de las capacidades personales (can do) para la realización personal, las representaciones que han sido catalogadas de posfeministas deben más a una tendencia evolutiva de la construcción de la feminidad paralela al feminismo (lo que la autora denomina, a falta de un término más ajustado, neofeminismo), relacionada con la adaptación del sujeto femenino a los requerimientos del neoliberalismo más que con las prerrogativas de reforma social feministas.

Además de dotar de agencia sexual a las mujeres representadas, otra estrategia del posfeminismo para configurarlas como mujeres empoderadas en el campo de las representaciones contemporáneas es asignarles comportamientos agresivos (Inness, 2004; Gill, 2008). La tendencia a crear imágenes de mujeres duras y agresivas puede encontrarse, en diversos grados, en las series televisivas (Inness, 2004; Ross, 2004; Tung, 2004), el cine (Gabbard y Gabbard, 1993; Bernárdez, 2002; Brown, 2004) y los vídeos musicales (Tortajada y Araüna, 2010; Guarinos, 2012; Tortajada, 2013). Según Inness (2004), el fenómeno de la mujer dura tiene arraigo en la tradición americana, con un acerbo representativo de mujeres extraordinariamente hábiles en el uso de la fuerza por lo menos desde Calamity Jane. A finales del siglo XX, el cine comercial ha vuelto a conectar con este acerbo a través de un cambio en la representación de las mujeres, que dejan de ser exclusivamente víctimas de la brutalidad masculina y pasan a ser presentadas como 
personajes legitimados a ejercer la violencia y escapar del círculo de la victimización previo (Bernárdez, 2002). Cabe destacar tres elementos en esta nueva caracterización de los personajes femeninos: para empezar, la crueldad de estas mujeres se acompaña de la erotización de su imagen (Gill, 2008); en segundo lugar, es una crueldad justificada por la necesidad de venganza (Boyle, 2005; Gill, 2008; Tortajada \& Araüna, 2010; Araüna, 2012); $y$, finalmente, este modo agresivo de relacionarse con los personajes masculinos no resta a esas mujeres atractivo ni glamour sino que, contrariamente, los incrementa (Wang \& Sik Ying Ho, 2007).

Hay algo específicamente contradictorio en las abundantes representaciones de mujeres agresivas del último decenio (Gill, 2008), puesto que a la vez que estos personajes se apropian de rasgos tradicionalmente masculinos -como el ejercicio de la violenciatambién encarnan los códigos clásicos de la feminidad mediante la sexualización y el cosmetismo (Gill, 2009; Lazar; 2009). Por lo tanto, estas mujeres duras combinan una doble dimensión: la de chicas guerreras (girls who kick ass) y la de fashion divas (Tung, 2004). Su exuberancia y extravagancia se acompañan de una independencia y determinación no exentas de cierta actitud agresiva (Guarinos, 2012). Pero, a pesar de que estas nuevas representaciones muestran a una mujer poderosa y activa (Gill, 2008), no dejan de inscribirse en un marco de discurso que a menudo las "pornifica" y que justifica la sexualización femenina (McRobbie, 2004). De ahí que el poder y la autonomía incrementados de esas mujeres se mezcle, a través de una serie de diversas restricciones y regulaciones, con un énfasis en rasgos femeninos tales como la maternidad, la feminidad o la sexualidad (Inness, 1999; Bernárdez, 2007). Según McRobbie (2006), es necesario interrogarse sobre la complejidad de las posiciones de las mujeres vistas o representadas como poseedoras del poder. Este el objetivo del análisis de los vídeos musicales de Madonna que presentamos a continuación.

\section{Madonna}

Madonna es una de las artistas más representativas en la evolución del formato del vídeo musical (Kellner, 2003). Madonna ha sido objeto de debate en el ámbito académico por su ambigüedad y por lo contradictorio de su posición a propósito del género. Entre sus defensoras, Kaplan (1987) sugiere que la artista encarna una identidad dicotómica que le ofrece libertad porque no encaja en las rígidas categorías patriarcales. En este mismo sentido, McClary (1991) propone que la indefinición tonal en la música de Madonna se relaciona con su indefinición identitaria. Y Lewis $(1990,1993)$ añade que Madonna utiliza en sus vídeos signos de acceso (apropiación de objetos y espacios tradicionalmente masculinos) y signos de reconocimiento (reivindicación de los objetos y espacios femeninos como fuente de solidaridad entre mujeres) para construir identidades susceptibles de empoderar tanto a las artistas como a los públicos femeninos. Mistry (2000) matiza que, si bien Madonna desestabiliza el sistema binario de géneros que fundamenta la heternormatividad porque su representación tiene elementos transgresores, su condición de icono del pop mainstream la pone bajo sospecha de instrumentalizar las 
subculturas (principalmente gay y transexual) en su propio beneficio, como también apuntan Whiteley (1997) y hooks (2012).

Respecto a los modelos de feminidad, Kellner (2003) afirma que Madonna ofrece la imagen de una mujer cosificada que promueve valores ligados al consumo pero, al mismo tiempo, un repertorio de identidades emancipadoras. Tanto Fiske (1997) como Kellner (2003) consideran que, aunque Madonna se presente a sí misma como un objeto sexual para el disfrute de la mirada masculina, sus constantes guiños y su posición ante la cámara revelan que sabe lo que se hace y que controla su propia imagen, lo que tiene mucho que ver con los rasgos posfeministas que acabamos de describir. Fiske (1997) y Kellner (2003) hacen una lectura positiva de esta cosificación irónica, pero las teóricas que analizan el posfeminismo y el neofeminismo opinan que es una nueva forma de sexismo.

Así, hooks (2012) considera que a partir de los noventa, Madonna, que había sido un icono de resistencia en contra de las representaciones estereotipadas de la mujer, se somete a la economía de la mirada patriarcal, objetualizándose e intentando mostrar la imagen de una chica joven y sexy, epítome de la supremacía racial blanca y heterosexual. hooks (2012) incluso acusa a Madonna de expresar sentimientos antifeministas de ultraderecha en el álbum Sex, que bajo una aparente forma transgresora estereotipa y patroniza las subculturas gay y llega incluso a expresar una visión misógina de la violencia de género. Además, Madonna somete a otras mujeres, especialmente cuando éstas son negras, con lo que consagra el orden sexual y racial heredado. De ahí que esa misma autora llegue a compararla con la vigilante de una plantación que voyeuriza tanto los cuerpos racializados como las prácticas sexuales no normativas (Hooks, 1992). Para Hooks (2012), desde la publicación de Sex, Madonna prioriza el hedonismo y la encarnación de una madre fálica, que a la vez es el ideal de feminidad blanco y rubio, tomando posiciones de poder que subordinan al resto de mujeres y hombres, especialmente a los no heterosexuales ni blancos, y que están muy alejadas de metas y valores feministas.

\section{Metodología}

Este estudio tiene como objeto de análisis el vídeo musical, que ha sido definido como un género transmediático (Viñuela, 2009) y típicamente posmoderno (Kaplan, 1987). Aunque los vídeos puedan ser narrativos, Sedeño (2007) destaca que dicha narratividad no es la meta principal sino que lo es el mecanismo descriptivo seductor a través del cual se centra el interés sobre los objetos anunciados, en este caso, músicos y cantantes. En este mismo sentido, Frith (1988) plantea que, a pesar de ser un producto promocional, el principal objetivo del vídeo musical no es tanto la venta directa como la creación de una estrella, apoyando la construcción de una imagen e identidad para una artista. Las imágenes de los vídeos son tan poderosas que estructuran la significación dominante de la canción hasta el punto de que la mayoría de espectadores y espectadores la interpreta en base a las imágenes más que a la letra (Whiteley, 1997). 
Después de revisar toda la videografía de Madonna, analizamos aquellos vídeos que incluían algún tipo de violencia física o simbólica (catorce en total), centrándonos en la posición que, en relación con el género, tenían los personajes que participaban en las acciones violentas. Podemos clasificar los vídeos de Madonna según si ella es la víctima que sufre estas acciones o la agresora que las ejecuta. Detectamos un punto de inflexión a partir de la primera mitad de la década de los noventa con el vídeo "You'll See", en el que Madonna rehuía la posición de víctima que había encarnado en "Take a Bow", vídeo del que "You'll See" es una secuela. A partir de ahí, en vídeos posteriores, cuando hay violencia, Madonna es la agresora y los hombres, el blanco de su agresión. La reflexión que presentamos a continuación profundiza ese primer estudio en lo que las imágenes de feminidad que ofrece Madonna respecta mediante el análisis cualitativo de cuatro de sus vídeos musicales: "Express Yourself" (1989, del álbum Like a Prayer), "Bad Girl" (1993, del álbum Erótica), "What it Feels Like For a Girl" (2001, del álbum Music) y "Give Me All Your Luvin'" (2012, del álbum MDNA).

\section{La reconfiguración de la feminidad en los vídeos de Madonna}

"Express Yourself" (1989)' es una canción y vídeo musical de Madonna. La letra de la canción es un himno a no conformarse, a expresarse (uno o una) tal como quiere ser, a no dejarse avasallar por la situación y a dejarse llevar por esa "mano fuerte" capaz de llevarnos a un estado mejor (una mano fuerte que no tiene por qué ser otra que la de nuestro propio impulso personal). El vídeo nos muestra un caso particular del mensaje de esa letra. Básicamente, la escena está formada por unos hombres semidesnudos y musculosos que representan los obreros de una peculiar cadena de montaje de la primera mitad del siglo XX, semiesclavizados incluso por su patrono, un hombre rico y elegante que vive en su ático de lujo, situado muy por encima del nivel de la fábrica. El personaje que encarna Madonna - mujer fetichizada- canta y baila desde ese piso superior. Elegantemente vestida y enjoyada, se nos muestra como el particular juguete caro de ese patrono, para quien aparece en momentos incluso encadenada por el cuello como un animal de compañía. Esa imagen de felino doméstico se acentúa también porque, en varios momentos, ella aparece con un gato negro en el regazo al que acaricia repetidamente. Aun así, pese a que la mayoría de planos nos muestran el cuerpo y rostro de la mujer en posturas y composiciones sugerentes, los primeros cuerpos que vemos, después de los planos de situación, son los torsos de los obreros, en los que el vídeo se recrea a modo de espectáculo erótico visual. Esto indica que el deseo que se expresa en primer lugar es el de ella. La peculiaridad de la mujer fetichizada que aparece en "Express Yourself", pues, es que ella también es un sujeto deseante. Las imágenes sugieren que la mujer es activa en la seducción. De todos modos, aunque la puesta en escena la privilegia dándole los espacios superiores, esa presunta ventaja sólo se traduce en su cotización erótica como objeto sexual. Dentro de su espacio de confinamiento, consigue

1 FINCHER, David. Express Yourself. 1989. [https://www.youtube.com/watch? V=GsVcUzP_O_8] consultado el 17 de octubre de 2014. 
reivindicar su agencia mediante el goce sexual hedonista, pero sin cambiar en el fondo ni su estatus ni las condiciones de su existencia.

El montaje de las escenas comienza a mostrarnos un paralelismo entre la situación de sometimiento de la mujer objeto del patrono y la de los obreros de ese mismo empresario. Mientras Madonna invita a que nos expresemos libremente, su gato sale de su lado y acaba colándose en la estancia de los trabajadores, donde es recogido por el atractivo obrero que parece ser objeto principal del llamamiento de la cantante. El gato representa ese espíritu felino capaz de liberarnos si lo sabemos aprovechar. Ella lo tiene y lo deja escapar para compartirlo con el operario, que, al verlo, también despierta el suyo. Se produce en ese momento una pelea entre los trabajadores que distrae al patrón y que es aprovechada por el obrero en cuestión para subir al piso en el que se encuentra recluida la cantante y consumar con ella la liberación simbólica mediante una relación sexual.

Podría decirse que el vídeo aúna un llamamiento a la liberación femenina y a la liberación obrera como dos formas de un mismo sometimiento por parte del varón capitalista dominante. Lo cierto, sin embargo, es que la liberación que se nos presenta en realidad es la del obrero, que se rebela contra su amo, consigue acceder al espacio de poder y se "lleva" a su chica. No queda tan claro que ésta se libere del mismo modo, sin embargo. A fin de cuentas, se encuentra con el trabajador en la misma estancia recluida en la que estaba. Y si bien puede decirse que establece con él una relación sexual de igualdad, cariño y romanticismo que no existía con el patrón de la fábrica, no queda claro hasta qué punto esa liberación va más allá del plano puramente sexual y sentimental: Madonna no se hace con el mando de la fábrica, ni derrota al varón que la sometía. Puede decirse, en todo caso, que rompe sus cadenas sin revanchismo, sin intención de venganza.

En "Bad Girl" (1993)2, la letra de la canción nos habla de una mujer desdichada que no es capaz de demostrar sus verdaderos sentimientos hacia el hombre que ama, lo que la empuja a una conducta que ella misma se reprocha: bebedora y fumadora compulsiva, tiene relaciones sexuales con un hombre distinto cada noche. El vídeo musical nos retrata a la que podría ser esa mujer, pero nos enseña únicamente una parte: la de sus idas y venidas con los hombres, a los que solamente utiliza como objetos sexuales. En cualquier caso, sin embargo, también ella es usada como objeto sexual por ellos. Deducimos que es ahí donde radica el fundamento de su infelicidad.

El personaje de su vídeo, interpretado por ella misma, es una mujer de gran éxito profesional (una alta ejecutiva) que dedica sus noches a cazar hombres en forma de conquistas sexuales. Pero sabemos ya desde un principio que la suya es la historia de una tragedia anunciada. En las primeras escenas, vemos que la policía entra en su domicilio para descubrir el cadáver de la protagonista. A partir de ahí, la trama funciona a modo de flashback en el que se nos cuenta cómo ha llegado a tan triste final. Vemos también que, durante todo el tiempo, ha estado vigilada por un ángel de la guarda que, en

2 FINCHER, David. Bad Girl. 1993. [https://www.youtube.com/watch?̨=JUII7DTACf4] consultado el 17 de octubre de 2014. 
cualquier caso, y salvo algún que otro guiño argumental intrascendente (como, por ejemplo, cuando apaga la llama de un encendedor soplándola desde el otro extremo de la estancia donde ambos se encuentran o cuando le da un gélido beso de despedida la noche en la que es asesinada), no interviene en las escenas de la vida de la protagonista. Sólo al final, cuando ésta muere, pueden ambos interactuar, en el otro mundo, donde, mirándolo a él, ella parece entender finalmente lo que le ha sucedido durante todo ese tiempo. Es significativo también que el vídeo termine con un plano superpuesto (y medio fundido) del rostro de ella. Sorprende el semblante de paz que muestra entonces, como si la muerte hubiera sido una liberación a su penosa vida de sujeto utilizador/objeto utilizado. También acentúa esa impresión el intercambio de gestos que mantiene una vez muerta con su ángel de la guarda.

En todo el vídeo no hay alusión alguna a ese hombre a quien, según la canción, ama, pero al que no puede demostrar su amor. No puede decirse que esa figura esté sublimada en el ángel de la guarda que la vigila, pues nada indica que ella lo haya conocido hasta el momento final de su muerte. Esta elipsis de una figura tan importante en la letra de la canción solo puede entenderse como un mecanismo simplificador de la narración visual del vídeo.

Caracterizada como femme fatale, con abundancia de claroscuros y referencias al cine negro, la mujer a la que Madonna encarna en pantalla es una triunfadora en ámbitos tradicionalmente masculinos como el mundo de los negocios y el espacio de la conquista sexual. Pero si, por ese lado, pone en cuestión el poder patriarcal, por otro es doblemente castigada: su promiscuidad sexual la hace profundamente infeliz y, además, es asesinada por uno de sus desconocidos amantes. Ese doble castigo reinstaura una desigualdad entre los géneros.

"What it Feels like for a Girl" (2001)33, mucho más reciente, es el vídeo en el que Madonna apuesta por caracterizar a una mujer con un perfil más claramente agresivo. La cantante, de nuevo protagonista del vídeo, arremete indiscriminadamente contra todos los hombres que se cruzan en su camino. El vídeo no está basado en ninguna relación sentimental específica sino que la protagonista del vídeo se rebela contra una masculinidad abstracta que ha sido opresora histórica de la mujer, aunque uno de los planos muestra golpes en su cuerpo que podrían aludir a un incidente o relación de maltrato que no se especifica ni en la letra ni en el vídeo, pero que en cualquier caso asienta un indicio de una posible narrativa de venganza o redención. Las imágenes muestran a la mujer conduciendo de forma temeraria y colisionando contra todos los hombres que se encuentra por el camino; para emprender esta venganza, el personaje femenino lleva de copiloto a una señora mayor, lo que parece indicar la voluntad de implicar en la revancha a una mujer que ha sufrido a lo largo de su vida esta opresión.

3 RITCHIE, Guy. What it Feels like for a Girl. 2001. [https://www.youtube.com/watch?v=qYwgG2oyUbA] consultado el 17 de octubre de 2014. 
Diferentes elementos relativos a la feminidad y a la masculinidad entran en juego en el vídeo musical para crear un universo simbólico donde el género tiene un papel estructurador fundamental. En este sentido el tema del vídeo funciona acorde a la canción, que aunque no relata ninguna actividad agresiva, sí que se dirige a un hombre al que relata las dificultades de ser mujer. La problematización de género en la canción es clara desde la primera frase, que incluso cuestiona la capacidad subversiva de la adopción de símbolos masculinos por parte de las mujeres: "Las chicas pueden llevar vaqueros / y el pelo corto / ponerse camisas y botas / porque está bien ser un chico / pero, para un chico, parecerse a una chica es degradante / porque vosotros creéis que ser una chica es degradante"4. Es interesante que aunque la canción hable de las dificultades de ser una mujer, hay una representación de la cantante con rasgos que combinan códigos de ambos géneros. La protagonista viste un mono oscuro, relativamente masculino, pero con unos zapatos de tacón y unos pendientes que marcan su feminidad. En clave irónica, en la matrícula de su coche ejecutor puede leerse "Pussy Cat", alusión a una consigna machista sobre la mujer que va a ser un contrapunto irónico a las acciones que la protagonista emprende con el coche. El tipo de comportamiento chulesco así como los espacios por los que se moverá la llevan a competir contra los hombres con los que se encuentra en actividades masculinas, con una dosis de agresividad que la proclama vencedora. Es en este sentido que deviene una encarnación de mujer fálica, otorgándose los atributos del universo masculino y compitiendo en el terreno de los hombres.

Concretamente, el personaje femenino se enfrenta a personajes que encarnan la estereotipación de la masculinidad, construyendo una mirada de oposición hacia ésta. Son chicos jóvenes que desde otro vehículo en el carril contiguo la miran lascivamente y se le insinúan, hombres que sacan dinero de un cajero -lo que podría ser interpretado como símbolo de avaricia-, o policías que en lugar de patrullar toman refrescos y comida basura, además de hombres orgullosos de su vehículo caro y deportivo. Ejemplos de lascivia, chulería y autoridad, todos son heridos, golpeados o humillados por la mujer. Los chicos del coche son embestidos, el hombre del cajero es agredido con un aparato de descarga eléctrica, los policías son humillados con una pistola de agua y rayándoles el coche, un grupo de chicos de distinto origen étnico que juegan un partido de hockey son atropellados, y el hombre del coche deportivo y lujoso se ve desposeído de él.

En todo momento vemos a la protagonista serena, calmada y decisiva en sus movimientos. La letra de la canción, si bien no propone ni describe acciones agresivas contra los hombres, si que acompaña la visualización de éstas, mediante un argumento reivindicativo dirigido a los hombres en el que les pregunta cómo se sentirían ellos si fuesen mujer: "¿Sabes lo que se siente siendo una chica? / ¿̇abes lo que se siente en este mundo siendo una chica?"5. Un diálogo que parece destacar la imposibilidad de comunicación con el otro género y la necesidad, en consecuencia, de la acción violenta.

\footnotetext{
4"Girls can wear jeans / and cut their hair short / wear shirts and boots / because it's OK to be a boy / but for a boy to look like a girl is degrading / because you think that being a girl is degrading".

5 "Do you know what it feels for a girl? / Do you know what it feels in this world / for a girl?".
} 
El vídeo termina con la acción decisiva del robo del coche y la explosión provocada de una gasolinera, acción destructiva que anticipa el final de la narración. Con tal de llevar a cabo el acto de venganza, la protagonista se sacrifica a ella misma. Así, por un lado el vídeo reivindica que las mujeres pueden -y quizá deben- utilizar la violencia para hacerse valer o vengar las afrentas del género masculino, y esta violencia, por lo tanto, sería un elemento empoderador. Por otro lado, el final del vídeo asume que la agresividad y las acciones violentas pueden destruir a quién las ejecuta y que, por lo tanto, la violencia es castigada. De este modo nos enfrentamos a un doble discurso; el del enaltecimiento de una agresividad femenina estilizada, a la vez que al castigo clásico sobre la mujer "mala" o amenazante, que es sancionada con la muerte al final de la historia, por legítimos que sean sus fines.

En "Give Me All Your Luvin'" (2012) 6 Madonna se acompaña de M.I.A. y Nicki Minaj para proponer una definición del amor que, en el vídeo, se representa irónicamente como un recurso al tópico de las armas de mujer. En este sentido, Madonna se empodera mediante la seducción, echando mano de su atractivo físico y actitud provocadora para conseguir que un ejército de jugadores de futbol americano, anonimizados por el uniforme y el casco, se sometan a sus deseos y le garanticen seguridad. Ya la sentencia con la que se abre el vídeo, a modo de pintada en un pared, es indicadora del valor estratégico de la seducción ("Iuvin'") para el éxito de la mujer: "Los fans pueden hacerte famosa, un contrato puede hacerte rica, la prensa puede hacer de ti una superestrella, pero solo el amor puede hacer de ti una buena competidora"7. Fundamentalmente, la letra de la canción supone la exigencia de Madonna a un potencial amante de que le entregue todo su amor y se esfuerce en complacerla en lugar de recurrir a lo que se espera de un hombre, que queda indefinido bajo la advertencia "No me vengas con juegos estúpidos"8. El valor crítico y empoderador que podría tener la canción se diluye con el argumento que la misma ofrece para justificar su petición "Porque yo no soy de esa clase de chicas" (o "porque yo soy una chica diferente")", individualizando la reclamación y atribuyéndola sólo a Madonna como mujer que es lo suficientemente dotada en términos de lo que se espera de su condición de género como para exigir una predisposición concreta del otro, pero no en términos de reivindicación colectiva de igualdad.

El vídeo reproduce esta jerarquización de hombres y mujeres, otorgando a Madonna que, en este caso, parece encarnarse a sí misma- la posición de superioridad y centralidad absoluta del producto, tanto a nivel compositivo como semántico. Además, ocupa también el mayor tiempo en pantalla y recorre el mayor espacio, con respecto a otros personajes. En este sentido podemos afirmar la clara dominancia de Madonna en este vídeo musical. Madonna también se distingue del resto de personajes del vídeo por su forma de vestir. En este aspecto es el único personaje claramente singular. Las artistas

6 MEGAFORCE TEAM. Give Me All Your Luvin. 2012. [https://www.youtube.com/watch? $\mathrm{v}=\mathrm{cltHO}$ (5LRWg] consultado el 17 de octubre de 2014.

7 "Fans can make you famous, a contract can make you rich, the press can make you a superstar, but only luv can make you a player"

8 "Don't play the stupid game"

9 "Cause I'm a different kind of girl" 
invitadas M.I.A. y Nicki Minaj, por su parte, visten casi todo el vídeo como animadoras y, aunque tienen un estatuto superior con respecto a la cohorte de animadoras enmascaradas (anonimizadas) que las acompañan, suelen situarse en posición inferior o posterior a Madonna, componiendo un triángulo. En este sentido, se puede detectar fácilmente la jerarquización de la mujer blanca -y rubia- que encarna Madonna con respecto al resto -M.I.A. y Nicki Minaj, pero también las anonimizadas animadoras morenas-. Aunque las cantantes invitadas se distinguen del resto porque llevan alguna variación del uniforme de animadoras, siguen ocupando un estatuto inferior a Madonna, y se dedican a cantar las partes de la canción que preparan para la otra. De hecho, el vídeo se inicia con el grupo de animadoras sosteniendo a sus espaldas a las artistas invitadas, que llaman a Madonna. Ésta sólo aparece segundos después, derribando una puerta lujosa, sobre la que emerge con un carrito de bebé y una gabardina y gafas de sol de star pasando desapercibida. La gabardina blanca y el color pastel de la puerta que pisotea, junto con el pelo rubio y la palidez, contrastan con los rojos y negros de que visten las animadoras. Luego, cuando caminan por la calle, Madonna lidera al grupo y las animadoras construyen una formación triangular detrás de ella. Este discurso visual sintoniza perfectamente con la reivindicación singularizadora e invidualista de la canción ("porque yo no soy de esa clase de chicas").

Desde el momento en que Madonna empieza su recorrido — jaleada por las animadorasunos jugadores de fútbol americano (imposibles de distinguir unos de otros bajo sus uniformes) se dedican a retirar diligentemente los obstáculos para que la artista no interrumpa en ningún momento su avance. La actitud de servicio a la mujer de ese grupo de hombres es absoluta, generando composiciones en momentos en los que ellos devienen escalones para que ella pueda subir muros, o la sujetan de modo que Madonna anda horizontalmente al suelo por la pared o, finalmente, amortizan su caída cuando, confiada, se lanza al vacío. De esta forma, y aunque la narrativa del vídeo implica peligros -en un punto, un coche tirotea a Madonna- ella avanza confiada de que su ejército de guardaespaldas la protege ante cualquier riesgo. Incluso cuando disparan contra ella, una sucesión de jugadores se lanzan e interponen con sus cuerpos la trayectoria de las balas. Esta acción metaforiza las aserciones de la canción "Dame un motivo / Dame todo lo que tengas / Igual te sale bien"10, que exige la entrega de su amante.

A partir de que el primer hombre que sale en el vídeo retira el obstáculo que frena el paso de Madonna, que anda en medio de la carretera, se empiezan a intercalar montajes de imágenes distintas de la artista que remiten a algunos de sus looks anteriores y más conocidos. Siempre rubia, en estas imágenes Madonna se presenta insinuándose, erotizada, seduciendo una mirada que hace plausible ante el espectador la sumisión de los hombres del vídeo. En la mayoría de estos insertos, más erotizados, Madonna viste de negro, excepto en el que vuelve a su look de Marilyn en "Material Girl" pero esta vez de blanco. Este es el único espacio en el que se permite una mayor igualdad cromática a las tres cantantes, que ahora visten de forma muy parecida; de blanco y con una peluca que emula el pelo de Marilyn; en este sentido parece proponerse cierta mutabilidad

10 "Give me a reason why / Give me all that you got / Maybe you'll do fine". 
racial. También es este espacio o salón donde las tres mujeres visten de blanco, un espacio íntegramente ocupado por lo femenino, donde se da una exhibición más sexualizada de los cuerpos de las mujeres.

Si al principio del vídeo la sumisión de los hombres ante Madonna se expresa por acciones como lanzar sus chaquetas al suelo encharcado para que ella pueda pasar, al final estas acciones devienen en el sacrificio de interponerse entre las balas. Al final del vídeo, Madonna y las animadoras se suben a hombros de los jugadores y bailan, hasta que una de las animadoras golpea la cabeza de uno de los jugadores, que Madonna toma en sus manos y levanta a modo de trofeo mientras el resto sacuden sus pompones. Todavía en un último plano, Madonna sostiene al muñeco que representa al niño del carrito con que se nos presentaba y, después de reír y saltar con gestos infantiles lo lanza fuera de campo — se oye incluso como golpea luego al suelo- y ella da una vuelta sobre sí misma riendo.

El imaginario de las cheerleaders así como la forma jovial de moverse y bailar de Madonna -en unos cuantos planos juega con su pelo de modo infantil-, además de su referencia a las imágenes que de ella misma ofrecía de joven, y las autoreferencias en la letra como una "chica" en lugar de una mujer, muestran un esfuerzo para construir una imagen de rejuvenecimiento de la imagen de la artista con respecto a sus producciones previas. Esta consagración del cuerpo femenino joven junto con los comportamientos sexualmente transgresores -que aquí se limitan a la exhibición y a librarse de la carga de la maternidad-parecen indicar que estos son los únicos recursos con los que cuenta la mujer para conseguir el dominio que tiene sobre los hombres del vídeo y, todavía más, que este dominio es una meta deseable. En este punto confluye la cabeza del hombre alzada como trofeo en el momento de la aclamación popular y la supresión de la maternidad, de modo simbólico -el bebé es un muñeco- pero aún un acto tomado de forma lúdica y liberadora para la cantante.

\section{Conclusiones}

Los vídeos musicales analizados refuerzan la constatación de varios autores de que, a lo largo de su trayectoria, Madonna ha jugado con las exhibiciones de género para poner en evidencia la mutabilidad y el carácter performativo de éstas. Ha representado y ha recreado diversos papeles (la mujer fetichizada, la femme fatale, la mujer sexy vengadora) que, a pesar de incorporar la explicitación del deseo sexual femenino y una cierta capacidad de agencia sexual, no necesariamente han trascendido los códigos visuales del patriarcado (Hooks, 2012). A partir de los noventa, se produce en sus vídeos musicales un cambio de posición en el eje de la violencia: las mujeres que Madonna encarna pasan de ser víctimas a ser verdugos. Y estas dos dimensiones de representación interactúan entre sí. Mientras que en "Bad Girl", la conducta sexual independiente que muestra Madonna como femme fatale se penaliza con la desdicha y con la muerte, en "Give Me All Your Luvin'" se premian el hedonismo y la dominación con la autorrealización y el éxito. 
Estos rasgos representacionales, junto con una apariencia cada vez más girlish, encajan con las descripciones de las imágenes posfeministas descritas por Gill (2007; 2008). Además, Madonna ha hecho suyos elementos de empoderamiento que sintonizan con el neofeminismo descrito por Radner (2011). Es decir, que la mutabilidad y el carácter de construcción identitaria que expresa en sus vídeos no serían necesariamente críticos con el sexismo y las representaciones de género tradicionales, sino fruto de un capitalismo de consumo que promueve la pluralidad de identidades en su propio beneficio.

Como parte de este contexto posfeminista, la violencia ejercida por mujeres viene siendo habitual en las representaciones mediáticas y, particularmente, en los vídeos musicales de mujeres artistas consagradas de gran éxito comercial (Tortajada, 2013). Madonna participa de esta tendencia y la promueve con diferentes recreaciones de una mujer sexualmente atractiva y vengadora. En "What It Feels Like For a Girl" las acciones ejecutoras que lleva a cabo la artista adoptan un tono solemne y presumen una actitud vengadora y reflexiva en torno al género. En cambio, en "Give Me All Your Luvin'", dichas acciones toman un tono lúdico, relacionando la sumisión y la agresión final con el poder seductor de la mujer sobre los hombres. Productos como "Give Me All Your Luvin'" demuestran que la seducción y el atractivo, a menudo, van unidos a estos perfiles agresivos que, como sugeríamos, han sido adoptados por otras artistas, y se han extendido en numerosos productos publicitarios y de ficción audiovisual. Si bien es obvio que, en la cultura comercial, las artistas siempre van a ser representadas como personajes altamente sugerentes para las audiencias, independientemente de si ejercen o no acciones violentas, cabe destacar que la agresividad se ha convertido en una estrategia fundamental para dotar a los personajes femeninos de interés.

Es particularmente significativo que en "Give Me All Your Luvin'”, uno de los últimos vídeos musicales de Madonna hasta la fecha, se la represente jugueteando con la figura de la maternidad: primero, presentándose con un cochecito de bebé; luego, amamantando socarronamente a un muñeco; y al final, arrojándolo al suelo como si fuera un balón. Todo esto parece expresar un desplazamiento del lugar ocupado por la maternidad, que, para esta cultura girlish, deja de tener una importancia central y pasa a adquirir un valor meramente periférico y secundario en comparación con la capacidad de consumo y el atractivo físico. La ausencia de relaciones estables en las autorrepresentaciones de Madonna en sus vídeos la encaja dentro del paradigma de la mujer soltera tal y como es definido por Radner (2011): delgada y de apariencia adolescente, le guía eminentemente el deseo de ser glamurosa y adorada por los hombres, la aspiración a disfrutar de independencia económica y el objetivo de que se le reconozca y se le respete su derecho al goce sexual.

En este sentido, Madonna habría sido una hábil constructora de imágenes e identidades cambiantes que, como hemos visto, ha dado pie a interpretar sus exhibiciones como rompedoras con las categorías patriarcales tradicionales (Kaplan, 1987). Sin embargo, y aunque parezca una contradicción, Madonna también ha mantenido una asombrosa coherencia a lo largo de los años porque tanto la mutabilidad como los rasgos intrínsecos a estas imágenes responden a las derivaciones de género del neoliberalismo. Esta 
consideración puede extenderse a la capacidad de Madonna para establecerse como estrella de la industria musical y como exitosa empresaria, y para ser una mujer de edad madura que cada vez parece más joven, lo que no deja de ser un parámetro de deseabilidad femenina, muy útil de cara a las ventas de cosméticos. Este excesivo control en la producción de su propia imagen visual ha llevado a que Madonna sea definida como la estrella perfecta de la era de la MTV, e incluso como una image-fascist. Y aunque esta crítica podría alimentarse del miedo tradicional a la mujer poderosa, también sugiere que hay de fundamentalmente de antiliberador en una artista con este aura de autocontrol (Reynold y Press, 1995).

Así, si bien podríamos alegar que las modulaciones de la feminidad propuestas en los videos musicales de Madonna, en tanto que hacen que esta rehúya la posición de víctima y encarne una figura agresiva, cuestionan el patriarcado, cabe argüir que estas imágenes alimentan una posición de sujeto individualista que toma los rasgos dominantes de la masculinidad y de la feminidad y que en modo alguno amparan una transformación de índole más colectiva. Por otra parte, el dominio de Madonna es un reflejo de las fantasías de poder femenino, pues en el mundo social real la violencia tiende a ejercerse en el sentido inverso, de hombre a mujer (Douglas, 2010). Además, estas fantasías exigen a las propias mujeres unos imperativos de competitividad no solo en sus ámbitos de siempre, sino también en las esferas tradicionalmente masculinas, pues el contexto de tardocapitalismo imperante requiere de sujetos femeninos económicamente independientes que, por paradójico que parezca, queden ligados así a las condiciones del mercado laboral y del consumo. 


\section{BIBLIOGRAFÍA}

ARAÜNA, Núria. "Gender violence and the representation of sexual and affective relationships: Reflections on cross-media research", Catalan Journal of Communication and Cultural Studies, vol. 4, n² (2012), pp. 143-153. DOI: 10.1386/cjcs.4.2.239_1

BERNÁRDEZ, Asunción. "Violencia y cine. El sabor amargo de una fascinación", en BERNÁRDEZ, Asunción (ed.), Violencia de género y sociedad. Una cuestión de poder. Ayuntamiento de Madrid, Madrid, 2002, pp. 87-108.

BERNÁRDEZ, Asunción. "Representación cinematográfica de la violencia de género femenino y masculino en el cine comercial español", Circunstancia, $n^{\circ} 12$ (2007), [http://www.ortegaygasset.edu/fog/ver/266/circunstancia/ano-v---numero-12---enero2007/ensayos/representacion-cinematografica-de-la-violencia-de-genero--femenino-ymasculino-en-el-cine-comercial-espanol], consultado el 7 de julio de 2014.

BOYLE, Karen. Media and Violence. Gendering the Debates, Sage, Londres, 2005.

BROWN, Jeffrey A. "Gender, sexuality and toughness: the bad girls of action film and comic books", en INNES, Sherrie A. (ed.), Action Chicks. New Images of Tough Women in Popular Culture, Palgrave Macmillan, Nueva York, 2004, pp. 47-74.

DOUGLAS, Susan J. The Rise of Enlightened Sexism. How Pop Culture took us from Girl Power to Girls Gone Wild, St. Martin's Griffin, Nueva York, 2010.

FISKE, John. Reading the Popular, Routledge, Nueva York, 1997.

FRITH, Simon. Music for Pleasure, Routledge, Nueva York, 1988.

GABBARD, Krin y GABBARD, Glen O. "Phallic Women in the Contemporary Cinema", American Imago, n०50 (1993), pp. 421-439.

GILL, Rosalind. "Postfeminist media culture: Elements of a sensibility", European Journal of Cultural Studies, vol.10, n² (2007), pp. 147-166. DOI: 10.1177/1367549407075898

GILL, Rosalind. "Empowerment/Sexism: Figuring Female Sexual Agency in Contemporary Advertising", Feminism and Psychology, vol.18, $\mathrm{n}^{\circ} 1$ (2008), pp.35-60. DOI: $10.1177 / 0959353507084950$

GILL, Rosalind. "Beyond the 'Sexualization of Culture' Thesis: An Intersectional Analysis of 'Sixpacks', 'Midriffs' and 'Hot Lesbians' in Advertising", Sexualities, vol.12, n², pp.137-160. DOI: $10.1177 / 1363460708100916$ 
GILL, Rosalind y SCHARFF, Christina. "Introduction", en GILL, Rosalind y SCHARFF, Christina (eds.), New Femininities: Postfeminism, Neoliberalism and Subjectivity, Palgrave McMillan, Basingstoke, 2011, pp. 1-17.

GUARINOS, Virginia. "Estereotipos y nuevos perfiles de mujer en la canción de consumo. De la romántica a la mujer fálica", Cuestiones de género: de la igualdad y la diferencia, n7 (2012), pp. 297-314.

hooks, bell. Black Looks. Race and Representation, Routledge, Nueva York, 1992.

hooks, bell. Outlaw Culture: Resisting Representations, Routledge, Nueva York, 2012.

INNESS, Sherrie A. Tough girls: women warriors and wonder women in popular culture, University of Pennsylvania Press, Pensilvania, 1999.

INNESS, Sherrie A. "Boxing gloves and bustiers: New images of tough women", en INNES, Sherrie A. (ed.), Action Chicks. New Images of Tough Women in Popular Culture, Palgrave Macmillan, Nueva York, 2004, pp. 2-17.

KAPLAN, Ann. Rocking around the clock: music television, postmodernism and consumer culture, Methuen, Londres, 1987.

KELLNER, Douglas. Media Culture. Cultural Studies, Identity and Politics. Between the modern and the postmodern, Routledge, Londres, 2003.

LAZAR, Michelle M. "Entitled to consume: postfeminist femininity and a culture of postcritique", Discourse \& Communication, vol.3, $n^{\circ} 4$ (2009), pp. 371-400. DOI: $10.1177 / 1750481309343872$

LEWIS, Lisa A. Gender Politics and MTV: Voicing the difference, Temple University Press, Filadelfia, 1990.

LEWIS, Lisa. A. "Being discovered. The emergence of female address on MTV", en FRITH, Simon, GOODWIN, Andrew y GROSSBERG, Lawrence (eds.), Sound and vision. The music video reader, Routledge, Nueva York, 1993, pp.129-152.

LOTZ, Amanda. "Postfeminist television criticism: Rehabilitating critical terms and identifying postfeminist attributes", Feminist Media Studies, vol.1, n¹ (2001), pp. 105-121. DOI: $10.1080 / 14680770120042891$

MCCLARY, Susan. Femenine Endings. Music, Gender, and Sexuality, University of Minnesota Press, Minnesota, 1991.

MCROBBIE, Angela. "Post-feminism and popular culture", Feminist Media Studies, vol.4, n³ (2004), pp. 255-64. DOI: 10.1080/1468077042000309937 
MCROBBIE, Angela. "Post-feminism and popular culture. Bridget Jones and the new gender regime", en CURRAN, James y MORLEY, David (eds.), Media and Cultural Theory, Routledge, Nueva York, 2006, pp. 59-74.

MISTRY, Reena. "Madonna and Gender Trouble". Theory.org.uk, 2000, [http://www.theory.org.uk/madonna.htm], consultado el 7 de julio de 2014.

RADNER, Hilary. Neo-Feminist Cinema. Girly Films, Chick Flicks and Consumer Culture, Routledge, Nueva York, 2011.

REYNOLD, Simon y PRESS, Joy. The Sex Revolts. Gender, Rebellion and Rock'n'Roll, Harvard University Press, Cambridge-Massachussets, 1995.

ROSS, Sharon. (2004) "Tough Enough: Female Friendship and Heroism in Xena and Buffy", en INNES, Sherrie A. (ed.), Action Chicks. New Images of Tough Women in Popular Culture, Palgrave Macmillan, Nueva York, 2004, pp. 231-256.

SEDEÑO, Ana María. "Narración y descripción en el videoclip musical", Razón y Palabra, 56, 2007, [http://www.razonypalabra.org.mx/anteriores/n56/asedeno.html], consultado el 7 de julio de 2014.

TORTAJADA, lolanda y ARAÜNA, Núria. "La representació de les relacions sexuals i afectives a les sèries televisives i als vídeos musicals", Observatori de les dones en els mitjans de comunicació,

2010 ,

[http://www.observatoridelesdones.org/articles_pdf/Larepresentaciodelesrelacions.pdf], consultado el 7 de julio de 2014.

TORTAJADA, Iolanda. "Divas vengadoras", en ZURIAN, Francisco, A. (ed.), Imagen, cuerpo y sexualidad. Representaciones del cuerpo en la cultura audiovisual contemporánea, Inserto-Colección Jesús Robles de textos de investigación audiovisual. Ocho y Medio, Madrid, 2013.

TUNG, Charlene. "Embodying an image: gender, race, and sexuality in La Femme Nikita", en INNES, Sherrie A. (ed.), Action Chicks. New Images of Tough Women in Popular Culture, Palgrave Macmillan, Nueva York, 2004, pp. 95-122.

VIÑUELA, Eduardo. El videoclip en España 1980-1995: gesto audiovisual, discurso y mercado. ICCM, Madrid, 2009.

WANG, Xiying y SIK YING HO, Petula. "My sassy girl: A qualitative study of women's aggression in dating relationships in Beijing", Journal of Interpersonal violence, vol. 22, n`5 (2007), pp. 623-638. DOI: 10.1177/0886260506298834 
WHITELEY, Sheila. "Seduced by the sign. An analysis of the textual links between sound and image in pop videos", en WHITELEY, Sheila (ed.), Sexing the Groove: Popular Music and Gender, Routledge, Nueva York, 1997, pp. 259-276. 